\title{
How did we let it come to this? A plea for the principle of continuity of care ${ }^{\dagger}$
}

\author{
George Lodge ${ }^{1}$
}

The Psychiatrist (2012), 36, 361-363, doi: 10.1192/pb.bp.112.038562

${ }^{1}$ Mental Health Review Tribunal, Wiltshire, UK

Correspondence to George Lodge (george.lodge@doctors.org.uk)

First received 13 Jan 2012, final revision 5 Mar 2012, accepted 29 Mar 2012
Summary The administrative imposition of new models of psychiatric care in the community has led to the fragmentation of services and a deteriorated experience for both service users and professionals. The author makes a plea for psychiatrists to reassert the principle of continuity of care, which has been all but lost from the practice of psychiatry during the past decade. It is possible to meet the clinical objectives of necessary support and treatment for service users within the community without the current multiplicity of team structures seen throughout England.

Declaration of interest None.
The introduction in the UK of the first really effective antipsychotic drug, chlorpromazine, in the early 1950s permitted the start of the process of emptying of our Victorian asylums. Further, the recognition of the potentially negative effects of institutional care led professionals to consider how patients' quality of life could be improved and how they might be cared for in a nearer normal environment in the community. ${ }^{1}$ The Mental Health Act 1959 was founded on the presumption that patients should not be repeatedly detained without adequate justification, and introduced a shift in emphasis towards caring for patients in the least restrictive environment. The subsequent run-down of England's large mental hospitals extended over about 40 years.

\section{The challenges of community treatment}

Caring for patients in the community required new services: out-patient clinics, day hospitals, occupational and industrial therapy, social work services and community nursing services. To be effective, different professional disciplines needed to work together, each providing their unique contribution but also coordinating their work and communicating with each other as part of a community team.

One persistent problem in caring for those with psychotic illness outside hospital was the loss of control of the patient's treatment. A sine qua non of psychosis is that individuals lack recognition that the symptoms they experience are caused by illness. Consequently, they often have difficulty in accepting their need for treatment. Further, like other, particularly young, people who have chronic or recurrent illnesses, they may have difficulty in accepting the need for continuing preventative treatment,

†See commentary, pp. 364-365, this issue. once symptomatically recovered. Although depot antipsychotics helped with the problem of unreliable oral dosing and showed improved relapse prevention, ${ }^{2}$ this invasive route of administration often proved unacceptable and could be refused once patients were no longer liable to detention. The unpleasant and stigmatising movement disorders and the sedating effects common with antipsychotic treatment also tended to make patients discontinue treatment, resulting in a revolving-door cycle of admission, discharge, disengagement, relapse and readmission.

Professionals therefore sought improved ways of supporting patients in the community to prevent relapse and readmission. The needs were clear: develop more acceptable, better-tolerated medication regimes; help patients and carers to have improved understanding of the illness and factors leading to relapse; empower patients to take positive control of their recovery; provide emotional and practical support to reduce stress and thereby reduce the risk of relapse; provide occupation to enhance selfesteem and reduce isolation; provide intensive support with medication-taking in the community.

During the 1990s, particular models of care which seemed to address some of these needs caught the imagination of influential minds at the Department of Health. A home treatment service in Sydney, Australia, showed reductions in in-patient bed usage and was more highly rated by patients and carers than the traditional service. ${ }^{3}$ Assertive home treatment services in the USA had also shown reduction in readmission bed days. ${ }^{4}$ The observation that the natural history of some patients with schizophrenia was of deterioration with successive relapses and a correlation between duration of untreated psychosis and prognosis led to the hypothesis that 'early intervention' might lead to a reduction in disability. ${ }^{5}$ The Department of Health was understandably enthusiastic about services that could potentially reduce disability and provide greater 
patient choice, but there was also an underlying assumption that this could reduce expensive in-patient care. Thus, National Health Service (NHS) trusts providing mental health services found themselves required to provide a range of services: crisis and home treatment, assertive outreach and early intervention. ${ }^{6}$ There was an expectation that these new services would pay for themselves by reducing relapse and morbidity as well as in-patient bed use.

Have these changes improved the overall quality of care or reduced disability? The changes were introduced without UK pilots to answer these questions. On the face of it, these new services seem to offer just those enhancements to community care that were needed, but the unintended consequences of re-focusing resources in the way that has occurred has not been examined.

\section{Research into practice and its unintended consequences}

There are obstacles to demonstrating that one service model is more or less effective than another. Those introducing a new approach are likely to be enthusiastic and to strive harder. Professionals prepared to go the extra mile for their cause are likely to be perceived more positively and rated more highly by service users. It is likely that these professionals will strive to achieve a reduction in bed usage when bed usage is a target measure. Research into new services has not looked at the consequential impact on services as a whole. As well as suffering from such difficulties, the original research that triggered this seismic change in our services was done in social and healthcare systems very different from those in the UK. 'Care as usual' in the UK often already included some of the components of these care models. Consequently, although the issue has been hotly argued, ${ }^{7,8}$ in contrast with the Australian and US research, the UK evidence base for home treatment compared with other community-based services has shown little or no benefit for assertive community treatment over standard care. ${ }^{9-12}$

Unsurprisingly, the prophecy of reduced bed usage has been self-fulfilling. Without new money, services were funded by closing wards. An unavoidable consequence of reducing available beds is that bed days used must reduce. Some UK studies have shown some modest advantage in readmission rates for early intervention over 'care as usual'. ${ }^{13}$ However, although duration of untreated psychosis may show a modest correlation with future disability, ${ }^{14}$ there is no evidence that early intervention reduces disability.

Typically, NHS trusts in England have implemented new services by creating autonomous teams, with each team having its own separate medical, nursing, occupational therapy, psychology and social work components. Funding for these teams has been drawn from in-patient services. The number of in-patient beds is now little more than a third of the number 20 years ago. ${ }^{15}$ Typically, each team determines its own case-load, criteria for accepting and discharging patients and how long it will care for them. Each phase of care is dealt with by a different set of professionals. No longer does one psychiatrist see a patient throughout their illness course. In those few hospital beds remaining, patients are often cared for by yet another different psychiatrist. No longer do service users experience any continuity of care. The patient's care pathway is to be repeatedly passed on. They do not have the opportunity to establish relationships with key professionals.

Hurried or perfunctory visits, missed appointments or unanswered telephone calls undermine service users' experience. $^{16}$ Not only is the care experience poor for service users, it is woefully inefficient for the NHS. Every change of team requires a handover process and a fresh assessment by the receiving team. All too often this may mean changes in diagnosis and treatment and every handover creates new opportunities for missed communication. Information and experience of the patient is lost at every move. Progress is put on hold while patients wait for assessments to determine whether they meet the criteria and whether the next team has the capacity to take them on.

Guidance urging long-term monitoring of severe and enduring mental illness ${ }^{17}$ is often ignored, with patients being lost to follow-up owing to a misguided application of the 'recovery' principle. ${ }^{18}$ The introduction of computerised notes, intended to make information on the patient readily available to all of these professional teams, in practice, paradoxically, appears to have reduced the amount of information recorded and its availability. The psychiatrist who has been caring for a patient in the community, who knows at least the recent history, has no power over the decision to admit. Crisis teams gate-keep access to hospital beds, ${ }^{19}$ their chief mission appearing to be to prevent admission. Often admission is simply delayed until compulsory admission becomes unavoidable. I recall one patient's summing up her experience with the words: 'I don't want to see the crisis team; it's always a different person and they never do anything'. Once in hospital, the pressure is to meet targets for early discharge with the spectre of financial penalties if targets are not achieved.

The reduction in beds now often means patients being admitted to hospitals far from home, including to expensive private hospitals. Out-of-area placement inhibits work with home teams and can prolong hospital stays. Pressure on beds means that voluntary admissions are rare and those wards that remain tend to be more volatile and, therefore, less therapeutic.

\section{How might we do things differently?}

There is, I believe, a ready consensus that we should continue to strive to: provide support to patients to remain at home, rather than come into hospital; provide intensive support to 'revolving-door' patients to assist them with day-to-day living and medication adherence; provide psychoeducation, family intervention and psychological support as well as medication advice and support to those struggling to accept a diagnosis of psychosis.

Where I would strive differently would be to end the current fragmentation of services and re-establish the principle of continuity of care. This would render services less wasteful and be welcomed by service users. As far as is possible, patients new to psychiatric services should be evaluated by the team who will continue to provide care for 
them, should it be needed. The management of a crisis at home can be incorporated into other care packages. ${ }^{20}$ If patients require more support than the community team can readily provide, such as out-of-hours care or frequent home visits, then a specialist team of nurses could provide temporary additional support working with, not independently of, the community team. If admission becomes necessary, then the psychiatrist who has known the patient through the course of their illness history is best placed to decide on this, to supervise that hospital treatment and to decide on discharge back to the same community team, with supplementary crisis support if necessary.

Individuals with psychosis, in particular schizophrenia, are likely to need help in coming to terms with and understanding their illness as well as support with recovery and medication-taking. Many may benefit from inputs like cognitive-behavioural and family interventions. This need is not confined to the newly diagnosed, it is often an ongoing issue for years. This type of approach should be bread and butter to community teams supporting those with psychoses, although they may also need specialist technical support in some skills and tasks such as cognitivebehavioural and family therapy.

There is an argument for maintaining an autonomous team in the area of rehabilitation and assertive outreach for those most likely to require readmission, based on the same principle of the need to maintain continuity of care for service users. Where patients have been identified as having a long-term illness and as being difficult to treat in the community, there is a need for an approach lasting over months and years rather than weeks, with regular and reliable support from staff who the patient knows and in whom they can develop trust. Return to the usual community team could then be contemplated when stability was achieved.

Encouragingly, there are still some services that do provide a level of continuity of care. There are many more professionals and service users who would wish to see a return to such continuity in the planning and provision of care as the basis of our psychiatric services.

This is a modest proposal. It does not reject the underlying science and philosophy of new services but pleads for an implementation that includes the concept of continuity. We must listen to the service users who become lost in this fragmented service and, at a time when draconian cuts in funding are looming, it is more than ever vital that the services we provide are as efficient as possible.

\section{About the author}

George Lodge, formerly consultant in general adult psychiatry with an interest in rehabilitation, Green Lane Hospital, Devizes, Avon and Wiltshire Mental Health NHS Partnership Trust; part-time medical member, mental health review tribunal; Fitness to Practise panel member (chair), General Medical Council; formerly psychiatrist member of the Parole Board.

\section{References}

1 Wing JK, Brown GW. Institutionalism and Schizophrenia: A Comparative Study of Three Mental Hospitals 1960-1968. Cambridge University Press, 1970.

2 Freeman $\mathrm{H}$. Pharmacological treatment and management. In Schizophrenia: Towards a New Synthesis (ed. JK Wing): 182-7. Academic Press, 1978.

3 Hoult J, Rosen A, Reynolds I. Community orientated treatment compared to psychiatric hospital orientated treatment. Soc Sci Med 1984; 18: 1005-10.

4 Stein LI, Test MA. Alternative to mental hospital treatment. I. Conceptual model, treatment program, and clinical evaluation. Arch Gen Psychiatry 1980; 37: 392-7.

5 Birchwood $M$, McGorry $P$, Jackson $H$. Early intervention in schizophrenia. Br J Psychiatry 1997; 170: 2-5.

6 Department of Health. A National Service Framework for Mental Health: Modern Standards and Service Models. Department of Health, 1999.

7 Marshall M, Bond G, Stein LI, Shepherd G, McGrew J, Hoult J, et al. PRiSM Psychosis Study. Design limitations, questionable conclusions. Br J Psychiatry 1999; 175: 501-3.

8 Thornicroft G, Becker T, Holloway F, Johnson S, Leese M, McCrone P, et al. Community mental health teams: evidence or belief? Br J Psychiatry 1999; 175: 508-13

9 Catty J, Burns T, Knapp M, Watt H, Wright C, Henderson A, et al. Home treatment for mental health problems: a systematic review. Psychol Med 2002: 32: 383-401.

10 Fiander M, Burns T, McHugo GJ, Drake RE. Assertive community treatment across the Atlantic: comparison of model fidelity in the UK and USA. Br J Psychiatry 2003; 182: 248-54.

11 Killaspy H, Bebbington P, Blizard R, Johnson S, Nolan F, Pilling S, et al. The REACT study: randomised evaluation of assertive community treatment in north London. BMJ 2006; 332: 815-20.

12 Johnson S, Nolan F, Hoult J, White IR, Bebbington P, Sandor A, et al Outcomes of crises before and after introduction of a crisis resolution team. Br J Psychiatry 2005; 187: 68-75.

13 Jones $\mathrm{P}$, Shiers D, Smith J. Early Intervention in Psychosis: Why a Specialised EIP Service Model is Preferable to a CMHT Model. Early Intervention in Psychosis, 2010 (http://www.iris-initiative.org.uk/silo/ files/head-to-head-eip-services-versus-cmhts-guidance-forcommissioners-and-service-planners.pdf).

14 Marshall $M$, Lewis $S$, Lockwood $A$, Drake $R$, Jones $P$, Croudace TA Association between duration of untreated psychosis and outcome in cohorts of first-episode patients: a systematic review. Arch Gen Psychiatry 2005; 62: 975-83.

15 Keown P, Weich S, Bhui KS, Scott J. Association between provision of mental illness beds and rate of involuntary admissions in the NHS in England 1988-2008: ecological study. BMJ 2011; 343: d3736.

16 Clark F, Khattak S, Nahal N, Linde K. Crisis Resolution and Home Treatment: the Service User and Carer Experience. National Audit Office, 2008.

17 Standing Nursing and Midwifery Advisory Committee. The Nurses Contribution to Assertive Community Treatment. Mental Health Nursing Addressing Acute Concerns (Practice Guidance). SNMAC, 1999 (http:// www.dh.gov.uk/prod_consum_dh/groups/dh_digitalassets/@dh/@en/ documents/digitalasset/dh_4074855.pdf).

18 Lodge GJ. Empowerment and the recovery model (letter). Psychiatrist 2010; 34: 116-7.

19 Department of Health. Statistical Press Notice: Mental health community teams activity data, 2011-12 Q3. Department of Health 2012 (http://mediacentre.dh.gov.uk/2012/02/03/mental-healthcommunity-teams-activity-data-2011-12-q3/)

20 Joy $C B$, Adams CE, Rice K. Crisis intervention for people with severe mental illnesses. Cochrane Database Syst Rev 2006; 4: CD001087. 